\title{
Serviço
}

\section{ORGANIZAÇÃO DE SERVIÇO DE ENFERMAGEM*}

\section{INTRODUÇĀO}

\author{
Circe de Melo Ribeiro **
}

Educação e Serviço são dois temas básicos que vem sendo debatidos nos 22 Congressos da Associação Brasileira de Enfermagem, desde 1926, sendo que maior ênfase sempre foi dada ao primeiro.

Pela peristência, insistência e valor das líderes da enfermagem brasileira muito já foi alcançado na área da educação. Todavia, na área de serviço a situação não se mostra com muitas evidências de resultados positivos. Com muita propriedade a Comissão Especial, designada em 1969 para elaborar a Política da ABEn, no diagnóstico da situação da enfermagem (1970), diz o seguinte:

"A qualidade e a quantidade de assistência de enfermagem são afetadas por problemas, uns intrinsecos as estruturas de saúde, e outros relativos ao próprio serviço de enfermagem... Quanto aos relativos ao serviço de enfermagem, fazem-se notar: 1) inexistência de modelos organizacionais de Serviço de Enfermagem; 2) inexistência de padrões brasileiros para cálculo de necessidade de pessoal de enfermagem; 3) inexistência de metodologia de enfermagem comprovada após experiência no País, para formulação de diagnóstico e desenvolvimento do plano de assistência de enfermagem; 4) inexistência de modelos para supervisão e avaliação do trabalho das diferentes categorias do pessoal de enfermagem; 5) inexistência de padrões mínimos para prestação de assistência de enfermagem a certos tipos de pacientes; 6) deficiência numérica de enfermeiras qualificadas para realização de um programa de pesquisa de enfermagem".

* Trabalho apresentado como documento básico do $10^{\circ}$ Seminário sobre Organização de Serviços de Enfermagem. realizado pela Comissão de Assistência da ABEn, SP.

** Membro da Comissão e Assistência de Enfermagem da ABEn-Seção de São Paulo e do Corpo Docente da EE. USP. 
Realmente esta é a situação-problema que teremos(1) que estudar e resolver, se é que desejamos o desenvolvimento e crescimento da profissão para dar à nossa população melhor assistência a. saúde, e em particular, assistência adequada de enfermagem.

Falar eternamente do déficit de enfermeiras no País não nos vai ajudar muito. Há que encarar o outro lado do problema: a questão da qualidade dos quantitativos atuais, da utilização plena e adequada dos profissionais de enfermagem de nível superior disponíveis e da sua responsabilidade pelo próprio desenvolvimento profisisonal.

As docentes das Escolas de Enfermagem e, principalmente as chefias dos Serviços de Enfermagem têm grande responsabilidade na solução dos problemas levantados acima, os quais além de afetarem a qualidade da assistência de enfermagem trazem sérios prejuízos ao ensino.

Educação e Serviço não se đivorciam, pelo contrário, integram-se, completam-se, e o melhor campo de aprendizado não é a escola, mas sim o trabalho, o serviço.

Se os campos de prática dos estudantes não estão bem organizados o aprendizado será incompleto, não alcançando a plenitude ciesejada e, dificilmente oferecerão oportunidade para o desenvolvimento sadio do espírito de liderança, de que tanto carece o País.

Como se não bastassem estas razões tão nobres para que sejam envidados todos os esforços possíveis para a melhoria dos serviços de enfermagem, surge uma outra, também forte: necessidade da pesquisa em enfermagem, tanto no que interessa à formação de docentes para a carreira universitária quanto, e, principalmente no que diz respeito à própria execução das atividades de enfermagem.

\section{OBJETIVOS}

Este seminário, organizado pela Comissão de Assistência de Enfermagem da ABEn - Seção de São Paulo, em colaboração com a Comissão de Educação, tendo em vista a atual situação da enfermagem hospitalar, tem como objetivos: oferecer subsídios às participantes para que novas diretrizes sejam impressas na organização ou reorganização dos serviços de enfemagem e oferecer oportunidade para discussões sobre os problemas que mais afetam a qualidade da enfermagem nos hospitais, onde trabalham. Ao lado destes podemos colocar um outro objetivo: dar oportunidade à Comissão de Assistência de melhor conhecer os problemas que as colegas enfrentam, 
de forma a poder imprimir uma linha segura de orientação ao seu trabalho, no cumprimento das normas estatutárias e regulamentares da ABEn (Anexo V).

\section{RECURSOS HUMANOS EM ENFERMAGEM}

Quando a ABEn realizou em 1957/8 o Levantamento de Recursos e Necessidades de Enfermagem no Brasil a situação era muito semelhante à atual. Isto se depreende da leitura do Relatório do Centro de Levantamentos - Capítulo II - "Enfermagem Hospitalar" e "Recomendações".

Havia então 1.390 hospitais com 176.296 leitos, 3.549 enfermeiras $(7,92), 6.904$ auxiliares de enfermagem $(19,37)$ e $25.337(70,82)$ atendentes(2) . Os problemas de organização de Serviço de Enfermagem eram exatamente os mesmos definidos em 1970, talvez hoje um pouco mais sérios. Em 1957 havia uma enfermeira para 49 leitos Em 1969, havia segundo IBGE, passou uma enfermeira para 51 leitos.

Em São Paulo (IBGE) a relação em 1967 era de 1/60 no Estado e 1/27 na capital. Não se pode negar que a situação na capital de São Paulo é quase satisfatória quando olhamos para a média; entretanto sabe-se que a distribuição de enfermeiras não é equitativa pelas casas de saúde. Os grandes centros hospitalares da capital, que representam cerca de $\mathbf{2 5 \%}$ do leitos existentes, absorvem perto de $70 \%$ das enfermeiras hospitalares disponiveis.

De qualquer forma não estamos acompanhando o desenvolvimento: o deficit de enfermeiras aumenta na medida em que há expansão dos serviços de saúde e maior demanda da população.

Dentro de uma programação racional não seria conveniente a concentração de grande número de enfermeiras em apenas 4 ou 5 grandes centros hospitalares. Todavia há certa vantagem em que isto aconteça, pois estes serviços se fortalecem e poderão produzir melhor tipo de assistência, produzir trabalhos científicos e criar entre os profissionais médicos e administradores um novo conceito da profissão, favorável a novas aberturas no mercado de trabalho para o maior volume de enfermeiras que se formará a partir do ano de 1970, como resultado da expansão das matrículas nas Escolas de Enfermagem a partir de 1967.

Para que tal aconteça, os serviços de enfermagem deverão ser muito bem organizados e contar com uma filosofia de trabalho que dê às enfermeiras maior motivação, sentido do trabalho em equipe, oportunidade para criar e inovar, oportunidade para educação contínua e pesquisas. 
No que diz respeito ao pessoal auxiliar em 1957 (ABEn) havia, no Brasil, um auxiliar de enfermagem para 25,5 leitos e um atendente para 7 leitos.

Em 1967 (IBGE) a situação modificou-se:

Brasil Est. São Paulo S. Paulo (Capital)

$\begin{array}{llllll}1 & \text { E } & / 51 & 1 / 60 & 1 / 27 & \\ 1 & \text { A. E. } & / 14,1 \text { leitos } & 1 / 16 \text { leitos } & 1 / 7 \text { leitos } \\ 1 \text { At. } & / 9 \text { leitos } & 1 / 6,3 \text { leitos } & 1 / 3 \text { leitos }\end{array}$

Segundo os cados acima na capital de São Paulo, para cada 100 leitos havia em 1967:

3,7 enfermeiras

14,3 auxiliares de enfermagem

33,3 atendentes

51,3 TOTAL

A OPAS/OMS, em 1960, recomendou para a América Latina, para 100 leitos 33 pessoas de enfermagem, das quais 6 enfermeiras e 27 elementos do grupo auxiliar.(4)

A expansão das matrículas nas escolas de enfermagem terá influência definitiva na melhoria do atual quadro de pessoal de enfermagem na Capital e nos Estados, especialmente quanto à relação enfermeira/paciente.

Aspecto da avaliação da assistência de enfermagem

Como já foi dito, é necessário que, além do aspecto quantitativo, seja considerado o da qualidade. Por exemplo, sabemos que nesta Capital o pessoal de enfermagem hospitalar está assim distribuido: enfermeiras $771(7,6 \%)$, auxiliares de enfermagem 2.879 $(28,3 \%)$ e atendentes $6.511(64,1 \%)$. Que atividades estão desempenhando as enfermeiras, as auxiliares e os atendentes? Há uma điferenciação de funções para cada categoria? Se existe, como funciona na realidade?

Não poderia certamente ser dada nenhuma resposta científica a qualquer dessas perguntas. Em primeiro lugar porque não foram feitas pesquisas a respeito e também porque após ter sido feita a primeira definição de funções, por categoria de enfermagem, a grande maioria dos Serviços de Enfermagem simplesmente passou a fazer uso dela, sem muitas vezes fazer qualquer adatação. 
Claro está que a situação quanto ao pessoal não é idêntica nos vários hospitais; a base do cálculo de necessidade de pessoal (quando empregado algum) não foi a mesma, as proporções entre as várias categorias variam, o nível de escolaridade dos atendentes varia, o tipo de hospital, de pacientes e de assistência também varia, enfim cada hospital é uma realidade única. Definição de funções é coisa que não pode ser padronizada no País; entretanto, lamentavelmente é o que se verifica, lendo algumas publicações sobre enfermagem.

A definição de uma filosofia de enfermagem necessária para dirigir e orientar a ação das chefias ainda não foi objeto sequer de cogitação na maioria dos serviços, no entanto, é essencial à formulação de uma política de ação e a elaboração de objetivos, normas e métodos de trabalho.

Também as pesquisas operacionais em enfermagem, recomendadas desde há alguns anos pelos nossos Congressos, não têm sido rea'izadas em grande escala. Até a presente data sabemos de apenas 3 completas e 2 incompletas. Sem este passo primordial para revisão dos Serviços de Enfermagem não iremos muito adiante no que diz respeito a utilização adequada do pessoal na prestação de assistência aos pacientes hospitalizados. Pelas poucas pesquisas de atividades já realizadas, verifica-se que enfermeiras, auxiliares e. atendentes estão executando as mesmas atividaces. Isto não deveria. ocorrer e para justificar esta idéia, basta considerarmos o custo de formação de uma enfermeira, de uma auxiliar e de um atendente. O nível de formação deve ser condizente com o nível de responsabilidades e de funçc̄es e vice-versa.

Se fôssemos enumerar todos os problemas que ainda obstaculizam o desenvolvimento da enfermagem brasileira perderíamos o sentido deste Seminário. Ficaremos portanto no primeiro problema citado pela Comissão Especial da Política da ABEn: inexistência de modelos organizacionais de serviços de enfermagem.

Scm pretensão de oferecer qualquer modelo procuraremos mais adiante definir um serviço de enfermagem bem organizado, sugerindo padrões ou normas.

\section{FUNÇÕES DA ENFERMAGEM}

Para definir um serviço de enfermagem e sugerir padrões de organização necessário fez-se algum comentário sobre o conceito de enfermagem em si e sobre sua problemática. 
De 1860 a 1960 não havia uma definição de enfermagem que fosse considerada internacional. Em 1960 o Conselho Internacional de Enfermagem (ICN) passou a adotar o conceito sobre a função peculiar da enfermeira, elaborada por Virgínia Henderson, para o folheto "Princípios Básicos sobre Cuidados de Enfermagem".

"A função peculiar da enfermeira é dar assistência ao indivíduo doente ou sadio no desempenho de atividades que contribuem para manter a saúde ou para recuperá-la (ou ter morte serena) atividades que ele desempenharia só, se tivesse força, vontade ou conhecimento necessário. E fazê-lo de modo que o ajude a ganhar sua independência o mais rápido possível".(5)

Quando considerarmos a prática da enfermagem sabemos que há uma variedade de categorias de pessoal-enfermeira, técnico de enfermagem, auxiliares de enfermagem e atendentes, executando as funções que a rigor são específicas da enfermeira. Tal variedade de categorias é plenamente justificável não só porque não há enfermeiras em número suficiente, em nenhum país do mundo, para assun ir todas as responsabilidades contidas no conceito citado, mas tambēm porq:ue as funçōes de enfermagem vão desde aquelas de natureza doméstica que exigem pessoal de enfermagem com preparação em serviço, até aquelas de maior complexidade e que exigem pessoal profissional com grande capacidade de julgamento, conhecimento científico e poder de decisōes.

A hierarquização das funções permite portanto a utilização de pessoal de diferentes níveis de preparação.

A forma clássica da piramide, para o cálculo de pessoal de enfermagem nos serviços, tem sido usada há muito tempo. Em pesquisa realizada nos Estados Unidos, em 1958, por Faye G. Abdellah, foi praticamente negada sua eficiência.(6) Pela resposta de pacientes a médicas, principalmente nos hospitais, onde era mais baixa a relação pessoal de enfermagem/paciente, havia maior satisfação com os cuidados de enfermagem. Ao analizar os dados, Abdellah verificou que nesses hospitais, em média, $65 \%$ do pessoal eram enfermeiras e os $35 \%$ restantes eram constituidos por auxiliares de enfermagem e atendentes. Um fato curioso foi registrado nessa pesquisa: as enfermeiras mostraram-se satisfeitas somente quando a relação pessoal/paciente era mais alta.

$\mathrm{Na}$ tabulação das respostas separando as clínicas obstétricas das clínicas gerais havia insatisfação quanto à assistência de 
enfermagem, tanto por parte de pacientes, de médicos como de enfermeiros.

Esta pesquisa foi mencionada apenas como exemplo para alertar as chefias de Serviços de Enfermagem e para mostrar que devemos sempre, em qualquer assunto, nos perguntar: será que o critério ou método que está sendo usado é o melhor? haverá outro que possa apresentar melhores resultados? Sem dúvida o espírito de indagação é uma condição essencial para a renovação de métodos, hoje tão propalada, porém tão pouco aplicada.

Ainda quanto ao aspecto qualitativo da assistência de enfermagem há que coǹsiderar o que se entende por bom cuidado de enfermagem, isto é, assistência de enfermagem de qualidade. Que critérios existem para medir qualidade?

Neste particular estamos ainda na era da pedra lascada; simplesmente nada temos de nosso a respeito do assunto e pouco existe na literatura estrangeira.

Somos do parecer que os critérios devem ser estabelecidos em termos de efeito da ação de enfermagem e estar baseados em padrões de cuidados.

Este é um assunto para pensar e estará em cada instituição, diretamente relacionado aos recursos humanos existentes. Estes, por sua vez, influem nos padrões estabelecidos pelo Serviço de Enfermagem.

Critérios de avaliação e padrões mínimos de cuidados de enfermagem poderão ser mais facilmente estabelecidos quando o corpo de enfermagem tiver definido sua filosofia e objetivo de serviço ou da prática da enfermagem e suas normas de trabalho.

\section{FILOSOFIA DO SERVIÇO DE ENFERMAGEM}

No prefácio da obra de Marshall Dimock diz Ordway Tead: "Uma filosafia diz respeito à validade básica, à justificativa e ao fundamento lógico de um corpo de atividades, tanto dentro de suas próprias fronteiras quanto em todas as suas ramificaçōes, incluindo sua significação em todo o conjunto da experiência humana. Basicamente nossa vida profissional não tem sentido, a menos que cada um trabalho utilizando uma filosofia que veja a dignidade humana e sua significação como critérios essenciais".

Administração é mais do que respostas aprendidas, técnicas bem escolhidas, ou um punhado de expedientes. Não chega a ser uma ciência e jamais deverá se tornar um método inflexível. $\mathrm{E}$ mais do que uma arte. É uma filosofia. 
Filosofia é um conjunto de crenças e práticas que objetivam melhor execução. A Administração trata de alvos e objetivos institucionais, de valores sociais e progresso individual, bem como de atividades acessórias de organizar e dirigir coisas que são apenas acidentais".(7) .

Dimock considera que uma filosofia de administração deve incluir e integrar todos os elementos que entram no processo administrativo, deve permitir a coerência de princípios e açōes, deve relacionar a fins e meios, acima das técnicas, deve oferecer um produto novo superior a soma das parcelas (valores, objetivos, elementos humanos, fins e meio, etc), que leve a uma completa satisfação e permita julgamento pelos resultados.

Toma como fundamentos básicos de uma filosofia de uma administração: o crescimento, a estłratégia, a liderança e a motivação.

O termo filosofia é usado por ele não no sentido de verdades finais que dizem respeito ao Universo, mas no sentido institucional de tentar descobrir os princípios da ação e condutas humanas que promovem a vitalidade da organização e o bem-estar. Sugere um catecismo filosófico para a Administração, que contenha os princípios básicos e orientadores da ação e da especulação.

Filosofia hoje, no sentido prático, leva não só à procura da sabedoria, mas à formulação clara do pensamento e ordenação do processo intelecíual. " $\mathrm{E}$ a causa pela qual se dinamizam as idéias e os esforços. E a força motriz das iniciativas e dos atos da instituição". (J. F. Carvalho) .

O pensamento filosófico alarga o horizonte intelectual, dá ao homem capacidade de perceber a realidade, a relação entre os fatos e entre os diversos campos do conhecimento, ajuda o homem a fazer julgamentos corretos, a pensar e principalmente, libertar-se do dogmatismo, dos automatismos e dos impulsos, levando a maior criatividade do pensamento

Aquele que sempre procura a verdade, a sabedoria, torna-se um pensador que terá maior facilidade de encontrar solução para uma situação problema.

A solução de um problema exige a formulação clara do mesmo, o que não é possível aos indivíduos dominados por reações impulsivas, que não são capazes de autocontrolar-se para pensar, de examinar a situação, relacionar fatos, elaborar hipóteses, julgar os valores sociais en ₹olvidos, ordenar o pensamento e então estabelece um plano estratégico para resolver o problema de forma global e integrada, relacionando fins e meios, bem como dando oportunidade ao crescimento de novas idéias.

$\dot{E}$ frequente na administração ouvirmos em várias reuniões seguidas, a colocação dos mesmos problemas, como indicação de 
que não foram resolvidos. Esta é uma consequência da falta de orientação administrativa sadia, e que constitui um dos fatores que leva a empresa a perder seu vigor e expontaneidade bem como a estabelecer regras e normas rígidas como falsa defesa contra 0 insucesso.

A elaboração de uma filosofia de administração compromete a tocios que dela participam no sentido de tomar seu papel na organização como missão e de assumir a responsabilidade de motivar o pessoal a participar das mesmas crenças.

Especialmente a formação de lídçres autênticos, equilibrados e, inventivos dentro da organização, depende de uma filosofia de administração, sendo que, quanto melhor preparados estiverem para tomar decisões, maior e mais equilibrado será o crescimento da instituição.

Em enfermagem nosso problema atual é a carência de líderes com aquelas características de autenticidade, equilíbrio, independência e espírito inovador. Falham nossos serviços pela falta de uma filosofia de administração.

Não nos aventuremos ainda a preparar para administração de Enfermagem, uma filosofia escrita, instrumento essencial para o planejamento e revisão dos serviços de Enfermagem Hospitalar e para julgamento dos resultados.

Uma filosofia de enfermagem serviria como plataforma que fornecesse os princípios básicos e orientadores da ação da enfermagem hospitalar e para a formação do "sprit de corps" de que nos falou Fayol.

O anexo I é uma sugestão preparada há 5 anos e poderíamos recomendar agora muito oportunamente sua análise.(8) Dissemos oportunamente porque deve preceder a qualquer estudo para organização ou reorganização de serviços de enfermagem, justamente o assunto deste encontro.

No sentido de oferecer mais elementos de juízo foi acrescentado o Anexo II que é a compilação da filosofia da prática de enfermagem, preparada pelo Corpo Docente do Colégio de Enfermagem da Universiciade da Florida.(9)

Neste seminário é nosso objetivo motivar as atuais ocupantes de cargos e direções de serviço de enfermagem a iniciar os estudos a respeito do assunto e para que no futuro os planos de trabalho reflitam uma filosofia de serviço, sadia e operante, traduzido nos postulados e princípios aceitos pelo corpo de enfermagem. 
"A força sem o espírito nada significa - torna-se coisa frágil. A força sem o indivíduo é uma casa de areia - não tem consistência.

A força sem grande número de indivíduos que se desenvolvem já está morta - perdeu seu potencial de crescimento".

\section{SERVIÇO DE ENFERMAGEM - NORMA DE ORGANIZAÇÃO}

O Anexo III trata de uma compilação feita de um documento não publicado, da Liga Nacional de Enfermagem(10) o qual deverá servir como base para o estudo que pretendemos fazer neste seminário. Como subsídio pará sua análise e para a elaboração de um documento que sirva de guia na organização de serviços de enfermagem o Anxo IV contém os padrōes mínimos considerados pelo Colégio Americano de Cirurgiōes e pela ABEn, como essenciais.(11)

Tratando-se de uma tarefa por demais pesada a ser imposta ̀̀s participantes, a elaboração de um documento-guia, julgamos de utilidade apresentar algumas sugestões de forma a facilitar o encaminhamento do problema.

Ao lado de algumas recomendaçōes para o estabelecimento de normas do S.E. seguem requisitos para facilitar avaliação da organização:

Norma I - O SE deve elaborar uma Filosofia de exercício da enfermagem (compatível com as diretrizes do hospital) da qual devem emanar os objetivos a serem alcançados e os princípios básicos.

Requisitos:

1. Todo o corpo de enfermeiras deve participar;

2. O documento deve ser amplamente divulgado, discutido e interpretado;

3. Cada área clínica de enfermagem deverá ter seu próprio documento, devidamente adaptado, segundo as características e necessidades próprias;

4. Devem ser revistos e reformulados periodicamente: filosofia e objetivos.

Norma II - O SE deve elaborar plano organizacional condizente com a filosofia, normas e princípios estabelecidos para o serviço de acordo com os planos gerais do hospital. 
Requisitos:

1. O plano deve ser bem definido quanto à organização estrutural funcional, de pessoal e de material;

2. O plano deve ser acompanhado de orçamento que permita sua execução e avaliação;

3. Elaboração a partir dos planos gerais do hospital.

4. Conter definição de responsabilidades, autoridade, e relacionamento inter e intra-departamental.

5. O plano deve definir o sistema de planejamento e estabelecer o sistema de comunicação no serviço.

Norma III - O SE deve desenvolver e implementar normas administrativas gerais e para seu pessoal.

Requisitos:

1. As normas deverão estar de acordo com aquelas estabelecidas para o hospital ou ser sua interpretação detalhada;

2. As normas deverão determinar como se processa a administração de pessoal no SE, incluindo qualificações e funçōes por categoria, sistema de recrutamento, seleção, admissão, colocação e desligamento;

3. Revisão (e reformulação) periódica das normas.

Norma IV - O SE deve desenvolver e implementar programas para o provimento de cuidados de enfermagem aos pacientes.

\section{Requisitos:}

1. Definição dos padrões de cuidados de enfermagem;

2. Técnicas básicas de cuidados de enfermagem;

3. Planejamento individualizado do cuidado e atualização;

4. Planos de enfermagem em acordo com os planos de assistência médico;

5. Prontuários devem revelar a qualidade do cuidado, o planejamento feito e nos resultados obtidos;

6. Distribuição de funções, nas áreas com as necessidades dos pacientes e qualificação do pessoal;

7. Planos escritos de supervisão e orientação de pessoal.

8. Revisão periódica (e reformulação) dos planos de programas de enfermagem.

Norma $V$ - O SE deve estabelecer um sistema para controle e uso de equipamentos, material e instalações. 
Requisitos:

1. Planos e normas por escrito para utilização máxima das instalações destinadas ao cuidado dos pacientes;

2. Elabcração de manual com especificação de todo o equipamento e material, condições para uso e conservação;

3. Programa para reposição de equipamento e material baseado em análises;

4. Revisão (e refcrmulação) dos planos e programas do sistema de controle.

Norma VI - O SE deve desenvolver e montar um sistema eficiente de relatórios e anotações clínicas e administrativas.

Requisitos:

1. Normas para comunicação à administração e corpo clínico.

2. Normas para comunicação intra e inter-departamental, dos resultados dos programas de ação da enfemagem;

3. Normas para comunicação de incidente e acidentes com pacientes e pessoal de enfermagem;

4. Normas para anotações clínicas nos prontuários;

5. Revisão (e reformulação) das normas do sistema.

Norma VII - O SE deve estabelecer planos e programas de educação contínua para seu pessoal.

Requisitos:

1. Planos a curto e longo prazos, de acordo com a filosofia, objetivos e princípios do SE;

2. Planos devem abranger todo o pessoal, com programas específicos para cada categoria;

3. Análise constante de situação para implementação adequada dos planos;

4. Previsão e participação do SE em outros programas da educação no hospital;

5. Revisão (e reformulação) anual dos planos e programas com todo o corpo de enfermeiras.

Norma VIII - O SE deve estabelecer um sistema de avaliação sistemática dos resultados:

Requisitos:

1. Sistema deve abranger o serviço como um todo e particularizar cada área clínica de enfermagem; 
2. Sistema deve definir o processo de avaliação dos resultados imediatos da ação de enfermagem;

3. Sistema deve incluir participação de pacientes, médicos e pessoal de enfermagem no processo de avaliação;

4. Cada fase do sistema deve ser relatada por escrito ao superior imediato e à administração do hospital;

5. Planos de pesquisas nas áreas clínicas;

6. Avaliação anual do sistema com todo o corpo de enfermeiras.

\section{CONCLUSÃO:}

A Comissão de Assistência de Enfermagem-ABEn - Seção de São Paulo não poderia oferecer qualquer tipo de assistência no campo de enfermagem hospitalar a menos que ouvisse os elementos das chefias de serviço. Esta oportunidade de reunir enfermeiras foi criada com o objetivo de tomar conhecimento dos problemas que afetam a qualidade da assistência de enfermagem em nosso meio e dai partir para planos objetivos de trabalho. Partindo do princípio de que cada um de nós tem alguma coisa boa que pode ser compartilhada, a Comissão, ao organizar este seminário, teve a idéia de, somando os esforços de cada um de nós, redigir um documento-guia para organização ou reorganização de serviços de enfermagem hospitalar. Subsídios foram acescentados para facilitar a discussão e elaboração do trabalho final.

\section{REFERENCIAS BIBLIOGRAFICAS}

1. Carvalho, J. F., LOzier, H. e CASTro, J. B. - Política da Associação Brasileira de Enfermagem. $R B E n 23$ (3, 4, 5 e 6):

109-118, dezembro 1970.

2. ASSOCIAÇÃO BRASILEIRA DE ENFERMAGEM - Relatório do Centro de Levantamento de Recursos e Necessidades da Enfermagem no Brasil, 1958 (material impresso em multiplicidade).

3. I.B.G.E. - Anuário Estatístico. São Paulo, 1969.

4. OPAS|OMS - A saúde na América e a Organização Mundial de Saúde.

5. HENDERSON, V. - Princípios básicos sobre cuidado de enfermagem. Rio de Janeiro, Fundo de Impressão da ABEn, 1962.

6. ABDELLAH, F. G. - Effects of nurse staffing on satisfaction with nursing care. Nurs. Res, 1960. p. 53.

7. DIMOCK, M. Filosofia da administração. $1 .^{\mathrm{a}}$ edição bras. Fundo de Cultura, 1967.

8. RIBEIRO, C. M. - Organização de um serviço de Enfermagem. RBEn 18(5): 495-505, dezembro 1965. 
9. FLÓRIDA, UNIVERSIDADE DA - Collsge of Nursing - Filosofia da prática de enfermagem, 1968 (material não publicado).

10. NATIONAL LEAGUE FOR NURSING - Normas para avaliação de serviço de enfermagem (material não publicado).

11. GARCIA, L. T. e RIBEIRO, C. M. - Padrões mínimos para organização de serviço de enfermagem. RBEn 21(5): dezembro 1970.

\section{ANEXO I \\ FILOSOFIA DO SERVIÇO DE ENFERMAGEM}

\section{Circe de Melo Ribeiro}

Citaremos, para exemplo, uma forma de encarar as responsabilidades de um Serviço do alto padrão, e que representa uma filosofia ou um credo de trabalho.

O Serviço de Enfermagem do Hospital $X$ é uma organização que se preocupa em dar assistência de Enfermagem individualizada, que atenda às necessidades físicas, psico-sociais e espirituais dos seus pacientes, com cuidados preventivos, curativos e de reabilitação, com igual interesse e dedicação a todos os pacientes, envolvendo seus familitares, numa diluição de responsabilidades, independente de influências sócic-econômicas, políticas ou culturais.

O Serviço de Enfermagem se preocupa com a assistência a todos os pacientes aceitos pela administração do hospital, quer seja nos ambulatórios, quer seja nas unidades de enfermagem ou clínicas, para o tratamento que buscam, como também pelos problemas de saúde da comunidade, interessando-se pela participação ativa para sua solução.

A direção o Serviço e Enfermagem crê no trabalho de equipe como o melhor método para atingir seus objetivos, através da valorização e melhor utilização do trabalho de cada membro da equipe.

Esta maneira de encarar as responsabilidades do Serviço de Enfermagem tem como pontos básicos os seguintes:

I - O paciente é o principal objeto e objetivo das atividades do Serviço de Enfermagem e representa uma constante força pressionadora, exprimindo seu desejos, suas expectativas e atitudes;

II - O paciente é uma personalidade individual com necessidades particulares quer no plano físico, mental, social ou espiritual que reage de acordo com suas crenças, esperanças para o futuro e experiências passadas; 
III - O paciente é uma pessoa que vem ao hospital à procura de auxílio e compreensão;

IV - O paciente deve receber cuidado integral de enfermagem, planejado segundo suas condições e suas necessidades físicas, mentais, sociais ou espirituais, quer sejam do ponto de vista curativo, de diagnóstico ou de reabilitação;

$\mathrm{V}$ - Todo o plano de cuidado, para ser bem sucedido, deve contar com a colaboração da pessoa para quem ele é planejado;

VI - A educação sanitária do pessoal e pacientes é um processo necessário que deve ser continuamente planejado pelo pessoal profissional de enfermagem;

VII - O Serviço de Enfermagem deve ser dinamizado através da ação, integração e dministração e do ensino, supervisão, avaliação e pesquisa;

VIII - A promoção das boas relações humanas no trabalho deve estar integrada em todas as atividades do Serviço de Enfermagem;

IX - A comunicação merece especial cuidado e planejamento em todas as atividades do Serviço de Enfermagem;

$\mathrm{X}$ - O bom funcionamento do Serviço de Enfermagem depende da aplicação correta dos princípios de administração;

XI - O funcionamento perfeito do Serviço de Enfermagem depende ainda da sua integração ao todo (hospital) e o desenvolvimento dos demais serviços;

XII - A crítica é instrumento útil e administração enquanto se constitue um impulso motivador para a melhoria do cuidado de enfermagem;

XIII - A qualidade do cuidado prestado ao público é o reflexo real do conceito de Enfermagem formado pelo Serviço de enfermagem;

$\mathrm{XIV}$ - As relações com a comunidade, à qual o hospital serve, devem ser mantidas através de contactos com os familiares, visitas e com a participação no estudo e soluções dos problemas de saúde desta comunidade.

A partir desses pontos, da filosofia exposta acima e das finalidades propostas para o hospital, serão então definidos os objetivos e as funções da enfermagem, podendo ser então planejado o serviço dentro de um realidade já. conhecida, através do levantamento das possibilidades e necessidades do hospital e da comunidade (dados do Projeto).

Os planos que então surgirem deverão ser discutidos pelo corpo de.enfermagem com a administração, num processo de coordenação contínua. 


\begin{abstract}
ANEXO II
FILOSOFIA DA PRÁTICA DE ENFERMAGEM

Elaborado pelo Corpo Docente do Colégio de Enfermagem da Un. Flórida/USA
\end{abstract}

Acreditamos que o mais nobre objetivo de enfermagem seja a administração do cuidado ao paciente, através da análise cientificamente fundamentada das suas necessidaes psico-fisiológicas e de reabilitação, como base para a devida intervenção e cuidado de enfermagem. Uma das maiores responsabilidades do Serviço de Enfermagem é criar uma ambiente no qual estudantes e enfermeiras recém-graduadas vejam a prática de enfermagem e o cuidado do paciente como interessante e como um desafio, e onde possam ganhar prestígio e satisfação pela maior eficiência e perícia como praticantes. Às enfermeiras devem ser dadas oportunidades para explorar e estudar meios de melhorar as relações enfermeira/paciente e os padrões de cuidado. Para conseguir isto devem ser aliviadas das atividades burocráticas e de gerência da unidade.

Nós ainda acreditamos que os aspectos profisisonais da prática de enfermagem vão além das habilidades de fazer as coisas até o processo intelectualizado de pensar, de analisar as necessiades de fazer tais coisas, de determinar a melhor maneira de fazê-las e de avaliar os resultados do processo. Para alcançar isto, a enfermeira, como verdadeira profissional, deve demonstrar habilidade na prática, capacidade para planejar, organizar e supervisionar o trabalho. Ela deve ser responsável pelo planejamento total dos cuidados a serem prestados aos pacientes a ela confiados. Para execução eficiente e inteligente do trabalho, a enfermeira deve possuir conhecimento das ciências do comportamento, dos princípios das técnicas e tratamentos, habilidade na observação, comunicação, relações interpessoais e capacidade de julgamento. Desde que não possa prestar todo o cuidado requerido, ela eve ser capaz de delegar aspectos do cuidado, de acordo com as necessidades dos pacientes, as funções específiicas a serem executadas e as diferentes habilidades do pessoal de enfermagem que trabalha sob sua direção.

Nosso compromisso é desenvolver esse modelo de papel de enfermeira, de forma que no hospital de ensino sejam oferecidos excelente cuidado aos pacientes e experiência para as estudantes. A responsabilidade do Serviço de Enfermagem é ainda provocar ati- 
tude de curiosidade entusiasmo das estudantes e profissionais, e desafiar a exploração posterior no que diz respeito ao ótimo do cuidado de enfermagem e a auto-avaliação, pela programação dinâmica e criativa da educação contínua.

\section{NORMAS BÁSICAS PARA SERVIÇOS DE ENFERMAGEM ORGANIZADOS*}

Um dos primeiros passos para a organização de direção eficiente de um Serviço de Enfermagem será deteminar os padrões ou normas de organização de acordo com os objetivos e funções de serviço.

\section{Objetivos das Normas}

Pretende-se que essas normas sirvam de instrumentos ao serviço de enfermagem para:

1. determinar sua posição na estrutura organizacional de modo a dar às enfermeiras responsabilidade, autoridade e meios para atuarem com eficiência no serviço;

2. desenvolver um plano de organização dos serviços de enfermagem focalizando o cuidado aos pacientes e a atualização adequada do pessoal;

3. fazer observar as funções dependentes, independentes e interdependentes do pessoal de enfermagem;

4. estimular o pessoal de enfermagem para que promova e/ou colabore com o ensino, estudos e pesquisas que afetam a enfermagem e o cuidado aos pacientes;

5. aplicar os princípios nos quais se baseiam a administração e o exercício da enfermagem;

6. avaliar sua própria eficiência como serviço e a eficiência de cada um dos elementos de sua equipe;

7. estabelecer critérios para auxiliar aqueles que devem avaliar os serviços de enfemagem.

\section{Premissas básicas}

São levadas em consideração as seguintes premissas:

1. as enfermeiras exercem a profissão nos serviços de enfermagem dos vários campos da saúde;

* Preparado pela N.L.N. Tradução de C. M. Ribeiro 
2. a qualidade da administração dos serviços de saúde e de enfermagem na qualidade da assistência de enfermagem prestada;

3. as normas dos serviços de enfermagem das instituições de saúde são estabelecidas por enfermeiras com conhecimento suficiente para determinar a qualidade do cuidado de enfermagem necessário aos indivíduos e famílias;

4. os aminisitradores e supervisores responsáveis pela direção dos. serviços de enfermagem e orientação das enfermeiras em serviço necessitam um preparo especializado em enfermagem clínica, em administração e supervisão;

5. a enfermeira em serviço necessita de educação continuada adicional ao programa básico;

6. o serviço de enfermagem tem responsabilidade total pela escala. de serviço de todo o pessoal de enfermagem;

7. os serviços de saúde se adaptam continuamente à mudanças sociais como, por exemplo, os progressos nos direitos civis;

8. as novas descobertas e a ênfase crescente na investigação continuarão ocasionando mudanças na prática da enfermagem e, portanto, continuarão afetando as normas que regem os serviços organizados de enfermagem.

\section{Critérios para a formulação de normas}

Uma norma formulada para servir de guia deve em si mesma obedecer a certos critérios; de outra forma permaneceria como mera. expressão lițrária, nunca destinada a se transformar em atividade com um propósito definido.

Critérios utilizados:

1. uma norma é estabelecida por uma autoridade reconhecida;

2. uma norma deve basear-se em um princípio;

3. uma norma traduz os objetivos e descreve as condiçōes necessárias para alcançar um ideal;

4. uma norma orienta, está estreitamente ligada às funções; de fato, normas e funções são ou devem ser interdependentes;

5. uma norma deve ser ampla, expressa de maneira clara e concisa para evitar ambiguidade e permitir interpretação fácil e exata. Deve ser formulada de forma a ser: a) adequada aos propósitos b) razoável e de realização possível c) aceitável por aqueles para quem foi formada e d) suficientemente definida para que possa determinar se foi ou não cumprida.

6. uma norma deve ser flexível; seu propósito não é estabelecer limites rígidos ou favorecer o conformismo, e sim proporcionar um guia que permita raciocínio e iniciativa; 
7. uma norma deve basear-se em teorias e práticas atualizadas e ao mesmo tempo estabelecer-se metas para melhorias;

8. uma norma e os critérios de avaliação que a acompanham devem estabelecer medidas para qualidade e quantidade dos serviços de enfermagem;

9. uma norma deve estar sujeita a contínua avaliação e revisão.

As normas e critérios para avaliação

I. O Serviço de Enfermagem (SE) estabelece uma filosofia $e$ formula objetivos que refletem os propósitos dos serviços de saúde e orientam o programa de cuidados de enfermagem

1. O pessoal de enfermagem é responsável pela formulação da revisão da filosofia e objetivos do serviço;

2. Todos os elementos do serviço recebem uma cópia da filosofia e dos objetivos do SE;

3. A filosofia e os objetivos são interpretados e postos à disposição dos elementos dos outros serviços.

4. Há evidências de que o SE baseia suas decisões na sua filosofia e objetivos;

5. A estrtura das comissões do SE estimula a execução dos objetivos do programa dos cuidados de enfermagem.

II - O SE tem responsabilidaile e autoridade em relação ao exercicio da enfermagem na instituição

1. O SE responde pela quantidade de cuidados de enfermagem prestada aos pacientes;

2. Os programas de cuidados de enfermagem se desenvolvem, continuam ou se ampliam de acordo com a disponibilidade de enfermeiras qualificadas, pessoal auxiliar e outras facilidades essenciais;

3. O SE toma decisões em relação à seleção, promoção e dispensa de pessoal.

III - O SE participa de todo planejamento e decisões tomadas na instituição, que afetam o funcionamento do serviço e o cuidado aos pacientes

1. As enfermeiras são membros de comissões que atuam na instituição e na comunidade;

2. Há normas definidas para as relações do SE com os outros serviços da instituição;

3. O SE colabora com os outros serviços no planejamento da coordenação de servị̧os que devem ser prestados aos pacientes. 
IV - O plano de organização do SE mostra sua estrutura funcional $e$ as relações entre o pessoal

1. O serviço está sob a direção de uma enfermeira que reune os requisitos estabelecidos pela instituição ou órgão competente.

2. As funções e qualificações do pessoal de enfermagem estão claramente definidas e de acordo com as funções e qualificações estabelecidas pela instituição ou órgão competente.

3. As responsabilidades do pessoal de enfermagem esfião claramente delimitadas e o responsável em cada caso pode ser identificado.

4. O plano de organização do SE prevê cargos para pessoal de enfermagem em número suficiente para proporcionar ao paciente cuidados de enfermagem seguro e terapêutico.

5. O plano de organização prevê utilização adequada de pessoal de enfermagem.

$\mathrm{V}$ - O SE conta com os recursos necessários para a realização de! seu programa

1. A diretoria do SE prepara o orçamento do serviço que é a parte do orçamento geral da instituição;

2. O orçamento do SE é elaborado com base nos objetivos que procura alcançar;

3. O SE mantém relatórios escritos de suas despesas, revistos e atualizados anualmente.

4. As necessidades imediatas e previstas de pessoal, equipamento e material são identificados e avaliadas em termos dos recursos financeiros que lhe forem determinados.

$\mathrm{VI}-\mathrm{O}$ SE provê cuidados de enfermagem seguros e terapêuticos por meio da aplicação de normas estabelecidas para o exercício da enfermagem

1. as enfermeiras revêem e atualizam os planos de cuidados de enfermagem sempre que necessário;

2. A enfermeira planeja, supervisiona e avalia o cuidado prestado a cada paciente;

3. O plano de cuidados de enfermagem está coordenado com o plano de assistência médica;

4. Ao planejar os cuidados de enfermagem são levadas em consideração as diferenças étnicas e religiosas dos pacientes, mas não existe diferença na assistência prestada por causa de raça, credo, cor ou posição social; 
6. A enfermeira determina o cuidado de enfermagem de cada paciente de acordo com suas necessidades, preparo e competência do pessoal de que dispõe;

7. A enfermeira presta cuidados de enfermagem aos pacientes cujo estado exige maior capacidade de raciocínio e habilidades especiais;

8. As anotações dos cuidados de enfermagem ao paciente refletem o seu progresso em relação à saúde, o planejamento dos cuidados de enfermagem e contribuem para dar continuidade à assistência que ele recebe.

9. Consultoria e apoio são proporcionados ao pessoal que planeja e executa os cuidados de enfermagem.

VII - O SE tem responsabilìades bem especificas no plano traçado pela instituição em situações de emergência.

1. O SE assume responsabilidade pela execução eficiente das fases do plano que corresponde à enfermagem.

2. Cada elemento da equipe de enfermagem está informado sobre o plano geral da instituição em casos de emergência.

3. Cada elemento da equipe de enfermagem, conhece, compreende e desempenha o papel que lhe cabe nos casos de emergência.

VIII - O SE possui regulamento que pode atrair elementos bem qualificados e auxilia a manter a estabilidade do pessoal da instituição

1. O recrutamento, seleção, colocação, conservação e promoção do pessoal de enfermagem estão baseados na capacidade e qualificação individual sem distinção de raça, credo ou cor;

2. Todo o funcionário novo recebe orientação quanto à filosofia, propósitos e política da instituição e do SE;

3. Os salários do pessoal do SE estão de acordo com sua qualificação e são equivalentes às posições de responsabilidade existentes na instituição e na comunidade;

4. Há norma estabelecida para garantir ao SE pessoal com as credenciais exigidas pelas leis vigentes;

5. Cada elemento da equipe de enfermagem tem acesso ao documento que descreve as tarefas que desempenha;

6. O pessoal de enfermagem auxilia na elaboração do regulamento do pessoal da instituição;

7. Cópias, tanto do regulamento do pessoal da instituição como do SE estão à disposição de cada elemento do serviço;

8. O SE auxilia a planejar e manter o programa de saúde do pessoal.

9. O SE mantém um sistema de registro do seu pessoal, coordenado com o exigido pelo serviço de pessoal. 
IX - O SE oferece programas de treinamento $e$ ıdá oportunidade para o desenvolvimento profissional do seu pessoal.

1. São desenvolvidos programas de treinamento para o pessoal auxiliar a fim de capacitá-lo com os conhecimentos e habilidades necessárias e auxiliá-lo a se ajustar ao novo ambiente;

2. Os programas para o desenvolvimento do pessoal utilizam os recursos educacionais internos e externos;

3. Elementos selecionados entre o pessoal são estimulados a se prepararem para cargos de maiores responsabilidades na enfermagem;

4. São feitos antecipadamente planos para preparar o pessoal selecionado para atuar em programas novos e mais amplos de assistência de enfermagem;

5. Elementos da equipe de enfermagem são estimulados a desenvolver seus interesses e atitudes vocacionais.

6. A instituição mantém uma biblioteca, com livros e revistas atualizadas e o pessoal de enfermagem é estimulado a dela fazer uso.

$\mathrm{X}$ - Quando a instituição tem também a função educativa, o SE participa na formulação das normas que vão afetar o cuidado aos pacientes, seu ambiente e o pessoal de enfermagem.

1. A responsabilidade da enfermeira pelo bem-estar dos pacientes sob sua supervisão é reconhecida pelas pessoas encarregadas dos programas educacionais;

2. São especificadas normas para manter alto padrão de qualidade de assistência a todos os pacientes e evitar danos aos mesmos;

3. O tipo e número de pessoas que utilizam a unidade clínica com qualidade educativa se mantêm dentro de limites razoáveis;

4. As facilidades para as pessoas que utilizam a unidade clínica para fins educacionais estarão especificadas.

$\mathrm{XI}$ - O SE tem convênio com as instituições educacionais que utilizam as facilidades clinicas para as estudantes de enfermagem, no qual são assegurados o bem-estar e a segurança dos pacientes

1. O SE é responsável pela assistência de enfermagem que deve ser prestada ao paciente.

2. A instituição educacional é responsável pela experiência de aprendizado e pela prática clínica dos estudantes.

3. O SE e instituição educacional planejam em conjunto as atribuições dos estudantes. 
XII - O SE participa na elaboração de normas que regulam a utilização da instituição para estuitos e pesquisas que podem afetar o cuidado dos pacientes, seu ambiente, ou o pessoal de enfermagem

1. São especificadas medidas para manter alto padrão de qualidade de assistência de enfermagem a todos os paciente e para prevenir danos aos mesmos;

2. O SE é informado com antecedência sobre os estudos e pesquisas que vão ser feitos;

3. A diretora do SE e o diretor de estudo ou investigação discutem as fases do projeto que irão envolver ou afetar o cuidado dos pacientes, seu ambiente ou o pessoal de enfermagem;

4. Ao formular a política a seguir são levados em consideração as implicações legais dos estudos e pesquisas que envolvem pacientes e pessoal;

5. Os resultados importantes dos estudos e pesquisas são compartilhados com o SE.

XIII - O SE inicia e promove estudos e, quando possivel, investigação das pnáticas administrativas, de supervisão $e$ de assistência de enfermagem

1. O pessoal de enfermagem auxilia a identificar áreas de estudo e investigação;

2. O pessoal de enfermagem envolvido tem acesso às informações sobre o desenvolvimento e o resultado dos estudos e investigações;

3. O SE incorpora às suas próprias atividades, os resultados que julgar aplicáveis.

$\mathrm{XIV}$ - O SE proporciona facilidades fisicas, de equipamento e material necessário à consecução dos objetivos e cumprimento das normas

1. São empregados métodos de avaliação bem definidos;

2. Elementos pertinentes à equipe de enfermagem avaliam os diversos aspectos dos serviços prestados pelo SE com o auxílio de membros da equipe de saúde quando necessário;

3. Os resultados das avaliações são utilizados para determinar os resultados do trabalho, identificar problemas, melhorar serviços e como base para o planejamento de novos programas. 


\section{ANEXO IV}

\section{PADRÕES MINIMOS PARA ENFERMAGEM EM HOSPITAIS}

American College of Surgeons(1918)

1. Organização: - Deve existir no hospital um departamento de enfermagem, bem organizado, sob competente direção e supervisão, para uma eficiente administração e prestação de serviços de enfermagem, quando mantém uma Escola de Enfermagem.

2. Pessoal: - Deve contar com número adequado de pessoal competente, treinado para a supervisão do serviço de enfermagem e para um cuidado de enfermagem eficiente de seus pacientes.

3. Facilidades: - Deve ter modernas facilidades convenientemente colocadas, com equipamento e material facilmente obtidos, para. o fornecimento de rápido e eficiente serviço de enfermagem.

4. Ėucação: - Quando uma escola de enfermagem é mantida em conexão com o Hospital, deve atender aos requisitos educacionais em conformidade com as exigências nacionais, adequado ao padrão de pessoal e facilidade para o ensino e completo sistema de secretaria escolar.

5. Prontuários: - Deve manter amplo sistema de anotações clínicas de enfermagem, incluindo todas as informaçōes pertinentes ao cuidado de enfermagem, observações de sinais e sintomas, execução das ordens médicas, prestação de serviço de enfermamagem, e outras informações que mostrem a condição do paciente e sua respostas ao tratamento.

6. Reuniões: - Reuniōes semanais do corpo de enfermeiros devem ser realizadas para revisão e análise do serviço de enfermagem, detcrrminação da qualidade do cuidado de enfermagem, prestado aos pacientes e melhoria de eficiência dos Serviços de Enfermagem quando indicado.

7. Em relação aos pacientes:- Cuidados completos devem ser prestados durante todo o tempo para assegurar um eficiente e seguro cuidado de enfermagem ao paciente por meio de escolas adequadas, supervisão competente dos estudantes de enfermagem quando em atividades dos cuidados ao paciente, bem como uma adequada proporção de número de enfermeiros. 


\author{
ANEXO IV \\ PADRÕES MINIMOS PARA SERVIÇO DE ENFERMAGEM \\ EM HOSPITAIS DE ENSINO \\ Amália Correa de Carvalho \\ (RBEn. 14(6) : 535-539, dez. 1961.
}

1. Manter Serviço de Enfermagem bem organizado, dirigido por enfermeira, e que ofereça boa assistência técnica aos doentes, com um serviço de enfermagem eficiente;

2. Ter na direção do Serviço de Enfermagem, enfermeiro preferivelmente com curso de pós-graduação, e que possua autonomia e autoridade na resolução de problemas técnicos de enfermagem e na seleção e preparo do pessoal;

3. Manter número adequado de pessoal de enfermagem, assegurando-se não sejam as estudantes de enfermagem levados a suprir o serviço de enfermagem do hospital, contrariando o objetivo primário da escola, que é a educação;

4. Ter, pelo menos um hospital-campo-de-estágio, uma enfermeira chefe, em cada um dos serviços básicos: medicina, cirurgia, centro cirúrgico, pediatria e obstetrícia;

5. Manter um programa de educação em serviço, a cargo do Serviço de Enfermagem, para a orientação e treinamento de pessoal récem-admitido e para o desenvolvimento de pessoal antigo, a fim de melhorar o padrão de cuidados prestados ao paciente:

6. Ter Regulamento e um sistema de anotaçōes adequadas, contando o Serviço de Enfermagem com manual de rotinas e técnicas, impressos próprios para o prontuário do paciente, normas e instruções escritas;

7. Manter clima propício para a observância do Código de Ética Profissional e para a colaboração dos enfermeiros do hospital no desenvolvimento dos alunos de enfermagem, facilitando seu aprendizado por meio do bom exemplo e de orientação e assistência quando necessárias;

8. Oferecer boas condições de trabalho, contando as unidades de enfermagem com as dependências essenciais e o equipamento e material inđaispensáveis ao cuidado do paciente, em quantidade suficiente e em bom estado de conservação, contribuindo para a melhoria da assistência prestada e para aplicação prática efetiva do aprendizado dos estudantes de enfermagem. 


\author{
ANEXO V \\ REGULAMENTO DO ESTATUTO DA ABEn
}

\title{
CAPITULO III
}

\section{DA DIRETORIA}

Art. 18 - À Comissão e Assistência de enfermagem compete:

I - traçar planos para o desenvolvimento das atividades e programas específicos, com o objetivo de propiciar melhoria da assistência de enfermagem ao público e das condições de trabalho do pessoal de enfermagem hospitalar, para-hospitalar e de saúde pública;

II - quando solicitada, orientar as Seções na organização e funcionamento de sua Comissão de Assistência de Enfermagem;

III - incentivar as Seções a desenvolverem programas de atua.lização e de educação em serviço para o pessoal de enfermagem;

IV - realizar estudos relacionados com problemas de enfermagem hospitalar, para-hospitalar e de saúde pública, que fujam ao âmbito das Seções;

$\mathrm{V}$ - divulgar na RBEn, e por outros meios, informações de caráter científico, sobre novos equipamentos e bibliografia, participando ativamente de movimentos relacionados com a assistência de enfermagem;

VI - apresentar balancete e relatório de suas atividades à Diretoria da ABEn e à Assembléia de Delegados;

Art. 25 - Ao coordenador de Comissão compete:

I - coordenar e dirigir os trabalhos de sua Comissão;

II - elaborar e submeter à aprovação da Diretoria, no prazo de 30 (trinta) dias após o início de seu mandato, o plano anual de trabalho e orçamento;

III - elaborar as normas de funcionamento de sua Comissão, submetendo-as à apreciação da' Diretoria;

IV - apresentar relatório anual e balanço financeiro à Diretoria da ABEn e à Assembléia de Delegados. 


\section{Evidências de planejamento e organização no Serviço de Enfermagem}

1. Declaração escrita da filosofia e objetivos do Serviço

2. Plano de organização

3. Manual administrativo

4. Manual de Técnicas básicas de Enfermagem

5. Orçamento e programa

6. Quadro de distribuição de pessoal

7. Planos de avaliação do cuidado de enfermagem (Auditoria em enfermagem).

8. Reuniōes Administrativas do Serviço

9. Comissões de Assessores em enfermagem

10. Material e equipamento adequado

11. Descrição e especificação de funções

12. Arquivos de pessoal

13. Normas de pessoal

14. Serviço de Saúde

15. Planos e programas de educação contínua para o pessoal

16. Reuniōes com outros departamentos. 